\title{
Tobacco dependence in the psychiatric population and in the general population
}

Renata Marques de Oliveira, Jair Lício Ferreira Santos, Antonia R. Ferreira Furegato Universidade de São Paulo

\section{Introduction}

Tobacco smoking is one of the main reasons for reduction in life expectancy among people with mental disorders. This Brazilian study aimed to compare the tobacco dependence between psychiatric and general populations

\section{Objective}

To estimate the tobacco dependence, identifying the factors independently associated, comparing the psychiatric population with the general population which attends the primary healthcare network.

\section{Materials and methods}

A cross-sectional epidemiological study was undertaken in Brazil.

A total of 134 smokers participated, who were attended in the Mental Health Outpatient Center (MHOC), the Psychiatric Hospital (PH) and in a Primary Healthcare Center (PHC). Individual interviews were held.

Poisson multiple regression model was undertaken using Stata/12.

\section{Results}

Of the 134 participants, $54.5 \%$ were female (mean age $=46$ years old).
While $49.1 \%$ of the psychiatric population (MHOC and PH) had an average/high degree of tobacco dependence, $58.3 \%$ of the smokers from the general population had very low/low dependence.

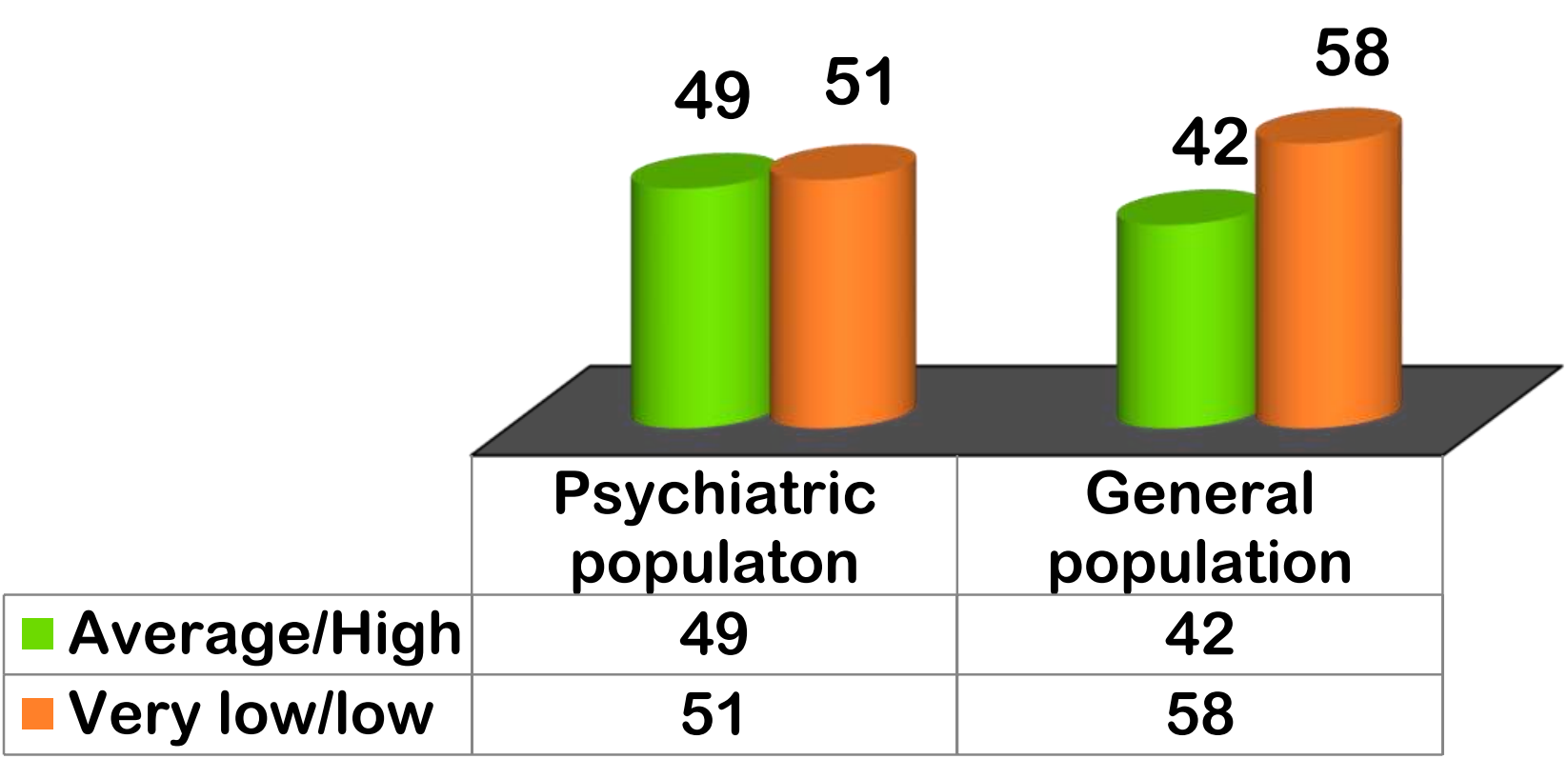

The Poisson regression model indicated greater prevalence of smokers with high dependence among the men ( $P R=1.41)$, people up to 49 years old (15-29 years old, $P R=4.06,30-39$ years old $P R=2.96,40-49$ years old $P R=1.84$ ), with severe mental disorders $\quad(P R=3.05)$ or anxiety disorders/others $(P R=3.98)$ and at high suicide risk ( $P R=1.55)$.

\section{Conclusion}

Tobacco dependence was significantly greater in the psychiatric population than in the general population assisted in the health services. The independent factors associated with intense tobacco dependence were sex, age group, psychiatric diagnosis and current suicide risk. These results help to improve the teams' awareness regarding tobacco in the psychiatric services. 